\title{
Extremely high prevalence of antiseptic resistant Quaternary Ammonium Compound E gene among clinical isolates of multiple drug resistant Acinetobacter baumannii in Malaysia
}

\author{
Mohammad Reza Babaei ${ }^{1}$, Anita Sulong ${ }^{2}$, Rukman Awang Hamat ${ }^{1}$, Syafinaz Amin Nordin ${ }^{1}$ and Vasantha Kumari Neela ${ }^{1 *}$
}

\begin{abstract}
Background: Antiseptics are commonly used for the management of MDR (multiple drug resistance) pathogens in hospitals. They play crucial roles in the infection control practices. Antiseptics are often used for skin antisepsis, gauze dressing, preparation of anatomical sites for surgical procedure, hand sterilization before in contact with an infected person, before an invasive procedure and as surgical scrub.

Methods: We screened 122 multiple drug resistant Acinetobacter baumannii (MDRAB) isolated from admitted patients in one of the tertiary care hospital in Malaysia for the presence of antiseptic resistant genes qacA and qacE (Quaternary Ammonium Compound) and susceptibility towards chlorhexidine (CLX), benzalkonium (BZK) and benzethonium (BZT).

Results: Eighty-nine (73\%) isolates harboured qacE gene, while none were positive for qacA. The MIC ranged from 0.2 to 0.6 for $C L X, 0.02$ to 0.2 for BZK and 0.04 to $0.2 \mu \mathrm{g} / \mathrm{mL}$ for BZT. The highest number of qacE positive isolates were obtained from surgery $(n=24 ; 27 \% ; p<0.05)$, followed by medical ward $(n=23 ; 25.8 \%)$ and ICU $(n=21$; 23.6\%). Majority of the isolates from wound swabs $(n=33 ; 37 \%)$, T/aspirate $(n=16 ; 18 \%)$ and tissue $(n=10 ; 11.2 \%)$ harboured the gacE genes.

Conclusion: The present investigation showed high prevalence of qacE gene among the studied isolates. Antiseptics are important components of infection control, continuous monitoring of antiseptics use in the hospital is cautioned.
\end{abstract}

Keywords: Antiseptic, Acinetobacter baumannii, Multiple drug resistance

\section{Background}

Multiple drug resistance Acinetobacter baumannii (MDRAB) ranks top among the nosocomial pathogen due to their environmental elasticity, ability to colonize various body sites of hospitalized patients, long-time persistence, association with multiple drug resistance and their successful outbreak potential [1-5]. It causes a wide spectrum of nosocomial infections which includes infections of bloodstream, urinary and respiratory tract,

\footnotetext{
* Correspondence: vasantha@upm.edu.my

${ }^{1}$ Department of Medical Microbiology and Parasitology, Faculty of Medicine and Health Sciences, Universiti Putra Malaysia, Serdang 43400, Malaysia Full list of author information is available at the end of the article
}

and ventilator associated pneumonia commonly among Intensive Care Unit patients (ICU) [6,7].

The main sources of transmission implicated with $A$. baumannii infections are person to person contact or through contaminated surface [8] and previous room occupancy by patients with $A$. baumannii infection or colonization. Epidemiological studies have clearly shown that hospital environment and colonized patients as the major reservoirs of $A$. baumannii infections [9]. Management of $A$. baumannii infections is the greatest challenge for patients, clinicians and infection control physicians. Infection control interventions such as patient screening, cohort isolation, hand hygiene compliance, surveillance of environmental contamination, enhanced cleaning and 
environmental disinfection have been shown to reduce nosocomial infection rates and outbreaks due to $A$. baumannii in various studies $[4,10,11]$.

Antiseptics are increasingly used in hospitals to control the dissemination of nosocomial infections. The regular use of antiseptics in hospital has raised concerns about its resistance. A very recent study by Suwantarat [12] has shown that bacteria causing life threatening infections in seriously ill patients are now becoming less susceptible to the commonly used antiseptics in the hospital. The study compared patients in ICU who received daily antiseptic washes with non ICU patients who did not receive any antiseptic baths. It was found that patients who received regular antiseptics baths showed less susceptibility to CLX compared to those who did not receive any antiseptic washes. Antiseptic resistance is encoded by the qac genes. To date several qac genes such as qac $A / B$ genes [13-15], qac $C / D$ also known as smr [15], qacE/F [16,17], qacG [18], qacH [19,20], qac J $[21,22]$ and qac $Z[23,24]$ have been reported. Qac A/B followed by qac $C / D$ genes is frequently associated with gram positive [25] and [26], while qac $E$ is commonly seen in gram negative bacteria.

Several studies from Asia including Malaysia have shown continuous increase of highly multiple drug resistant A. baumannii in Asia [27-30]. A recent study [27] demonstrated correlation between reduced susceptibility to disinfectants and multidrug resistance among clinical isolates of Acinetobacter species. Although several studies have shown the prevalence of antibiotic resistance in $A$. baumanni, only very few reports are available on the antiseptic and disinfectant susceptibility. In Malaysia, despite, A. baumannii being one of the serious nosocomial pathogen, its susceptibility towards antiseptics and disinfectant is largely unknown. Therefore, in this study we investigated the antiseptic and disinfectant susceptibility and carriage of corresponding resistant genes in A. baumannii isolated from patients admitted in one of the tertiary care teaching hospital in Malaysia. The study was conducted in Universiti kebangsan Malaysia Medical Centre, as it is in the capital of the country, which receives population from all over Malaysia. The rising trends of $A$. baumannii infections in the hospital prompted to investigate the antiseptic and disinfectant susceptibility.

\section{Methods}

\section{Bacterial isolates}

A total of 122 non-repetitive multiple drug resistance Acinetobacter baumannii (MDRAB) isolates collected from various clinical specimens ( 5 from blood, 41 wound swabs, 26 tracheal aspirate, 14 urine, 14 tissue, 10 sputum, 12 from others) from February 2012 to January 2013 from a 900 bedded hospital UKMMC was investigated. The isolates were confirmed in the hospital by the standard microbiological methods and also by AP 20NE (bioMérieux, France). The isolates were reconfirmed as $A$. baumannii by standard methods (oxidase, catalase, TSI, MRVP, Simmon citrate, motility, urease and Gram staining) in our laboratory stationed at Department of Medical Microbiology and Parasitology, Faculty of Medicine and Health Sciences, Universiti Putra Malaysia. An isolate is defined as MDRAB when it is resistant to more than three classes of antibiotics tested by disc diffusion test.

\section{PCR assay for qacA and qacE}

Total genomic DNA was extracted from MDRAB isolates using GF-1 Bacterial DNA Extraction Kit (Vivantis Technologies, Malaysia). All isolates were screened for the presence of qacA [31] (5'GCAGAAAGTGCAGAG TTCG-3' and 5' TCAACCGAATAGAGTGAACTTATC T-3') and $q a c E$ [32] (QacE F: 5'-GCGAAGTAATCGCA ACATCC-3' and Qac E R: 5' GCCCCATACCTACAAA GCC-3') genes. Two representative isolates for each gene was sequenced (First BASE Laboratories, Malaysia) and used as positive control. The sequence of the genes were confirmed by blastN program in GenBank (http:// www.ncbi.nlm.nih.gov).

\section{Antiseptic susceptibility}

All antiseptics chlorhexidine (CLX), benzalkonium (BZK) and benzethonium (BZT) were purchased from Sigma Aldrich (St Louis, MO, USA). A stock of antiseptics containing $100 \mathrm{mg} / \mathrm{L}$ of CLX, BZK and BZT in deionized water was prepared and stored at $4^{\circ} \mathrm{C}$. MICs of antiseptics were determined by the broth microdilution method according to the Clinical and Laboratory Standards Institute [1]. Since there was no standard breakpoints available for antiseptics against $A$. baumannii, we tested a 2 fold dilutions from $4 \%$ to $0.00006 \%$. A standard bacterial concentration of McFarland Standard $0.5\left(1.5 \times 10^{8} \mathrm{CFU} / \mathrm{mL}\right)$ was used. Briefly $50 \mu \mathrm{l}$ of bacterial suspension was added from well one to twelve in a 96 well plate. To well one, $50 \mu \mathrm{l}$ of $4 \%$ antiseptics was added. Upon mixing well, $50 \mu \mathrm{l}$ was transferred to next well and continued until last well. The dilutions included $4 \%, 2 \%, 1 \%, 0.5 \%, 0.25 \%$, $0.125 \%, 0.0625 \%, 0.0312 \%, 0.0156 \%, 0.0078 \%, 0.0039 \%$ and $0.0019 \%$. Susceptibility was interpreted based on the turbidity on the inoculum after incubation at $37^{\circ} \mathrm{C}$ for 24 hrs.

\section{Results}

Among the 122 isolates tested, qacE was found to be present in 89 isolates (72.95\%), none of the isolates carried $q a c A$ gene. In general for qacA positive isolates, the MIC ranged from 0.2 to $0.6 \mu \mathrm{g} / \mathrm{mL}$ for CLX, 0.02 to $0.2 \mu \mathrm{g} / \mathrm{mL}$ for $\mathrm{BZK}$ and 0.04 to $0.2 \mu \mathrm{g} / \mathrm{mL}$ for BZT. For qacE negative isolates, MIC ranged from 0.04 to 
$0.3 \mu \mathrm{g} / \mathrm{mL}$ for CLX, 0.01 for $0.08 \mu \mathrm{g} / \mathrm{mL}$ for BZK and 0.02 to $0.08 \mu \mathrm{g} / \mathrm{mL}$ for BZT. Highest qacE positive isolates were obtained from surgery $(n=24 ; 27 \%)$, followed by medical ward $(\mathrm{n}=23 ; 25.8 \%)$ and ICU $(\mathrm{n}=21 ; 23.6 \%)$ as illustrated in Tables 1 and 2. Isolation of qacE positive MDRAB was found to be significantly higher in the surgical ward $(\mathrm{p}<0.05)$. Majority of the isolates from wound swabs $(\mathrm{n}=33 ; 37 \%), \mathrm{T} /$ aspirate $(\mathrm{n}=16 / 18 \%)$ and tissue $(\mathrm{n}=10 / 11.2 \%)$ harboured the qacE genes.

\section{Discussion}

MDRAB is the biggest challenge for the infection control unit in every hospital setting. Growing resistance to every licensed antimicrobial agent against MDRAB including carbapenems to date has made this organism of global concern. Resistance rates may likely increase the treatment failures and mortality rates $[29,30]$. Unfortunate acquisition of MDRAB that leads to life threatening blood stream infections and pneumonia in the hospital could be prevented if proper hygienic measures are implemented, practiced and monitored regularly.

Antiseptics are widely used for infection control. They are applied to living tissue to reduce the possibility of infection, sepsis, or putrefaction and especially to keep the environment and the inanimate objects clean (for e.g. ventilators, catheter) from microbial communities. In the studied hospital, we found majority of the MDRAB isolates 89 (73\%) to harbour the qacE gene. However, the MIC for all the QAC's tested was far less than the concentration used in the hospitals $(0.5 \%-4 \% \mathrm{~mL} / \mathrm{liter})$ [33]. A study [34] showed higher MIC for $S$. aureus that harboured $q a c A / B$ gene. In the current study for MDRAB, no significant difference $(\mathrm{p}>0.05)$ was observed in MIC for qacE positive and negative isolates. The high carriage of qacE positive MDRAB in surgical ward $(\mathrm{p}<0.05)$ is not surprising as it is known that antiseptics are very frequently used in surgical wards to reduce the skin and soft tissue infections and also to reduce the postsurgical length

Table 1 Isolation of qacE positive MDRAB from different wards

\begin{tabular}{lll}
\hline Ward & \multicolumn{2}{l}{ Number of isolates (\%) } \\
\cline { 2 - 3 } & qacE positive $(\mathbf{n}=\mathbf{8 9})$ & $\boldsymbol{P}$ value \\
\hline ICU & $21(23.6 \%)$ & $>0.05$ \\
Neurosurgery & $2(2.2 \%)$ & $>0.05$ \\
Orthopaedics & $7(7.9 \%)$ & $>0.05$ \\
Urology & $4(4.5 \%)$ & $>0.05$ \\
Surgery & $24(27 \%)$ & $<0.05^{*}$ \\
Medical & $23(25.8 \%)$ & $>0.05$ \\
Burn & $2(2.3 \%)$ & $>0.05$ \\
Others & $6(6.7 \%)$ & $>0.05$ \\
\hline
\end{tabular}

$<0.05 *$ Indicates statistically significant.
Table 2 Isolation of qacE positive MDRAB from different clinical specimens

\begin{tabular}{lll}
\hline Clinical specimens & qacE positive $(\mathbf{n}=\mathbf{8 9})$ & $\boldsymbol{P}$ value \\
\hline Tracheal aspirate & $16(18 \%)$ & $>0.05$ \\
Wound swabs & $33(37 \%)$ & $>0.05$ \\
Tissue & $10(11.2 \%)$ & $>0.05$ \\
Blood & $4(4.5 \%)$ & $>0.05$ \\
Urine & $13(14.6 \%)$ & $>0.05$ \\
Sputum & $6(6.8 \%)$ & $>0.05$ \\
Others & $7(7.9 \%)$ & $>0.05$ \\
\hline
\end{tabular}

of stay and duration of antibiotic therapy [3]. Central venous $(\mathrm{CV})$ catheters are commonly used in the ICU as it plays crucial role in the management of critically ill patients.

In the current study, we found that majority of MDRAB isolates from ICU harbour qacE gene. Although the use of antiseptic impregnated catheters reduces catheter related bloodstream infections, emergence of antiseptic resistant strains are still on the rise. A recent study [34] reported high rates of $q a c A$ and $q a c B$ positive MRSA isolation from chlorhexidine impregnated catheter related bloodstream infections.

Stable resistance for antiseptics and antibiotics could be obtained for MDRAB when they are exposed stepwise with gradually increasing concentrations of QAC's as seen in Pseudomonas aeuroginosa and Eschericia coli $[34,12]$. This has also been shown in a metagenomic study which revealed that microbial community adapts to QAC when continuously exposed. A recent review has shown increasing evidence for co resistance and cross resistance between QAC's and other important antibiotics and disinfectants.

\section{Limitations of the study}

The main limitation of the study was samples from only one hospital in Malaysia were studied. As very limited data on antibiotic resistance pattern was available, antiseptic and antibiotic resistance could not be compared.

\section{Conclusions}

In conclusion, although the MIC of the QAC's tested against MDRAB is much lower than the concentration used in the hospital, the high prevalence of qacE gene in the studied isolates warns the continuous monitoring of antiseptics use in the hospital. 


\section{Authors' contributions}

MRB performed the laboratory work and analysis. AS provided the samples and clinical work. MRB, AS, RAH and SAN contributed in designing the study and preparation of the manuscript. All authors read and approved the final manuscript.

\section{Authors' information}

Mohammad Reza Babaei, Anita Sulong, Rukman Awang Hamat and Syafinaz Amin Nordin are co-authors.

\section{Acknowledgements}

This study was supported by Universiti Putra Malaysia through Research University Grant Scheme (04-02-12-1756RU). Authors thank Ms. Sunita binti Sulaiman from UKMMC for her support in sample and clinical information collection.

\section{Author details}

'Department of Medical Microbiology and Parasitology, Faculty of Medicine and Health Sciences, Universiti Putra Malaysia, Serdang 43400, Malaysia. ${ }^{2}$ Department of Medical Microbiology and Immunology, Faculty of Medicine, Universiti Kebangsaan Malaysia Medical Centre, Bandar Tun Razak, Cheras, Kuala Lumpur 56000, Malaysia.

\section{Received: 26 August 2014 Accepted: 24 February 2015}

\section{Published online: 11 March 2015}

\section{References}

1. Cockerill F. Performance Standards for Antimicrobial Susceptibility Testing: Twenty-second Informational Supplement. Clinical and Laboratory Standards Institute. 2012;32:M100-S22.

2. Le TAT, Dibley MJ, Vo V, Archibald L, Jarvis WR, Sohn AH. Reduction in surgical site infections in neurosurgical patients associated with a bedside hand hygiene program in Vietnam. Infect Control Hosp Epidemiol. 2007;28:583-8.

3. Manian FA, Griesenauer S, Senkel D, Setzer JM, Doll SA, Perry AM. Isolation of Acinetobacter baumannii complex and methicillin-resistant Staphylococcus aureus from hospital rooms following terminal cleaning and disinfection: can we do better? Infect Control Hosp Epidemiol. 2011;32:667-72.

4. Villegas MV, Hartstein Al. Acinetobacter outbreaks, 1977-2000. Infect Control Hosp Epidemiol. 2003;24:284-95.

5. Safdar N, Marx J, Meyer NA, Maki DG. Effectiveness of preemptive barrier precautions in controlling nosocomial colonization and infection by methicillin-resistant Staphylococcus aureus in a burn unit. Am J Infect Control. 2006:34:476-83.

6. Perez F, Hujer AM, Hujer KM, Decker BK, Rather PN, Bonomo RA. Global challenge of multidrug-resistant Acinetobacter baumannii. Antimicrob Agents Chemother. 2007;51:3471-84.

7. Bergogne-Bérézin E, Towener KJ. Acinetobacter spp. as nosocomial pathogens: microbiological, clinical and epidemiological features. Clin Microbiol Rev. 1996:9:148-65.

8. Otter JA, Yezli S, French GL. The role played by contaminated surfaces in the transmission of nosocomial pathogens. Infect Control Hosp Epidemiol. 2011;32:687-99.

9. Mak JK, Kim MJ, Pham J, Tapsall J, White PA. Antibiotic resistance determinants in nosocomial strains of multidrug-resistant Acinetobacter baumannii. J Antimicrob Chemother. 2009;63:47-54.

10. Rodriguez-Bano J, Garcia L, Ramirez E, Martinez-Martinez L, Muniain MA, Fernandez F. Long-term control of hospital-wide, endemic multidrug-resistant Acinetobacter baumannii through a comprehensive "bundle" approach. Am J Infect Control. 2009:37:715-22.

11. McDonnell G, Russell AD. Antiseptics and disinfectants: Activity, action, and resistance. Clin Microbiol Rev. 1999;12:147-79.

12. Nuntra S, Carroll KC, Tsigereda T, Tracy R, Maragakis LL, Sara C, et al. "High Prevalence of Reduced Chlorhexidine Susceptibility in Organisms Causing Central Line-Associated Bloodstream Infections". Infect Control Hosp Epidemiol. 2014;35:1183-6.

13. Meike B, Johann B, Petra P, Karin S, Gabriele M, Christina H. First Detection of the Antiseptic Resistance Gene gacA/B in Enterococcus faecalis. Microb Drug Resist. 2012;18:7.
14. McGann P, Kwak YI, Summers A, Cummings JF, Waterman PE, Lesho EP. Detection of gacA/B in clinical isolates of methicillin-resistant Staphylococcus aureus from a regional healthcare network in the eastern United States. Infect Control Hosp Epidemiol. 2011;32:1116-9.

15. Jeanes A, Rao G, Osman M, Merrick P. Eradication of persistent environmental MRSA. J Hosp Infect. 2005;61:85-6.

16. Heir E, Sundheim G, Holck AL. The gacG gene on plasmid pST94 confers resistance to quaternary ammonium compounds in staphylococci isolated from the food industry. J Appl Microbiol. 1998;86:378-88.

17. Ploy MC, Courvalin P, Lambert T. Characterization of $\ln 40$ of Enterobacter aerogenes BM2688, a class 1 integron with two new gene cassettes, Cm/A2 and qacF. Antimicrob Agents Chemother. 1998;42:2557-63.

18. Heir E, Sundheim G, Holck AL. Identification and characterization of quaternary ammonium compound resistant staphylococci from the food industry. Int J Food Microbiol. 1999;48:211-9.

19. Waage S, Even H, Jostein B, Terje S, Marianne S. Novel Plasmid-Borne Gene qacJ Mediates Resistance to Quaternary Ammonium Compounds in Equine Staphylococcus aureus, Staphylococcus simulans, and Staphylococcus intermedius. Antimicrob Agents Chemother. 2003:47:30486-3052.

20. Heir E, Sundheim G, Holck AL. The Staphylococcus qacH gene product: a new member of the SMR family encoding multidrug resistance. FEMS Microbiol Lett. 1998;163:49-56.

21. Braga TM, Marujo PE, Constanc P, Fa'tima Silva Lopes M. Involvement, and dissemination, of the enterococcal small multidrug resistance transporter QacZ in resistance to quaternary ammonium compounds. J Antimicrob Chemother. 2010;34:1-4.

22. Bjorland J, Steinum T, Sunde M, Waage S, Heir E. Novel plasmid-borne gene gacJ mediates resistance to quaternary ammonium compounds in equine Staphylococcus aureus, Staphylococcus simulans, and Staphylococcus intermedius. Antimicrob Agents Chemother. 2003;47:3046-52.

23. Zmantar T, Kouidhi B, Hajer H, Amina B. Detection of disinfectant and antibiotic resistance genes in Staphylococcus aureus isolated from the oral cavity of Tunisian children. Ann Microbiol. 2012;62:123-8.

24. Braga TM, Marujo PE, Pomba C, Lopes MFS. Involvement, and dissemination, of the enterococcal small multidrug resistance transporter QacZ in resistance to quaternary ammonium compounds. J Antimicrob Chemother. 2011;66:283-6.

25. Jean L, Christine S, Krystal S, Allison MG, Andrew S, Yves L, et al. Distribution of Antiseptic Resistance Genes qacA, gacB, and smr in Methicillin-Resistant Staphylococcus aureus Isolated in Toronto, Canada, from 2005 to 2009. Antimicrob Agents Chemother. 2011;55:2999-3001.

26. Noguchi N, Nakaminami H, Nishijima S, Kurokawa I, So H, Sasatsu M. Antimicrobial agent of susceptibilities and antiseptic resistance gene distribution among methicillin-resistant Staphylococcus aureus isolates from patients with impetigo and staphylococcal scalded skin syndrome. J Clin Microbiol. 2006:44:2119-25.

27. Kawamura-Sato K, Wachino J, Kondo T, Ito H, Arakawa Y. Correlation between reduced susceptibility to disinfectants and multidrug resistance among clinical isolates of Acinetobacter species. J Antimicrob Chemother. 2010:65:1975-83.

28. Gillespie MT, Lyon BR, Messerolti LJ, Skurray RA. Chromosome- and plasmid-mediated gentamicin resistance in Staphylococcus aureus encoded by Tn4007. J Med Microbiol. 1987;24:139-44

29. Cem Ç, Mustafa G, Fatma D, Mustafa Z, Nazif E, Esra G. Increasing antimicrobial resistance in nosocomial pathogens; multidrug-resistant extensively drug-resistant and pandrug-resistant Acinetobacter baumannii. J Microbiol Infect Dis. 2014;4(1):7-12. doi:10.5799/ ahinjs.02.2014.01.0116

30. Ghafur A, Vidya L, Priyadarshini K, Thirunarayan MA. Emergence of Pan drug resistance amongst gram negative bacteria! The First case series from India. J Microbiol Infect Dis. 2014;03:86-91. doi:10.5799/ahinjs.02.2014.03.0145.

31. Jeric PE, Azpiroz A, Lopardo H, Centrón D. Survey of molecular determinants in Gram-positive cocci isolated from hospital settings in Argentina. J Infect Dev Ctries. 2007;1:275-83.

32. Milstone AM, Perl TM, Passaretti CL. Chlorhexidine: expanding the armamentarium for infection control and prevention. Clin Infect Dis. 2008:46:274-81. 
33. Ho CM, Li CY, Ho MW, Lin CY, Liu SH, Lu JJ. High rate of qaCA- and qacB-positive methicillin-resistant Staphylococcus aureus isolates from chlorhexidine-impregnated catheter-related bloodstream infections. Antimicrob Agents Chemother. 2012;56:5693-7.

34. Thomas L, Russell D, Maillard JY. Antimicrobial activity of chlorhexidine diacetate and benzalkonium chloride against

Pseudomonas aeruginosa and its response to biocide residues. J Appl Microbiol. 2005;98:533-43.

Submit your next manuscript to BioMed Central and take full advantage of:

- Convenient online submission

- Thorough peer review

- No space constraints or color figure charges

- Immediate publication on acceptance

- Inclusion in PubMed, CAS, Scopus and Google Scholar

- Research which is freely available for redistribution 